\title{
Second Primary Malignancy in Patients with Hypopharyngeal Carcinoma: A SEER-Based Study
}

\author{
Liqing Guo $\mathbb{I D}^{\prime}$ \\ Yanpeng $\mathrm{Fu}^{\prime}$ \\ Chunyu Miao ${ }^{2}$ \\ Shuhong $\mathrm{Wu}^{\prime}$ \\ Yaqiong Zhu' \\ Yuehui Liu' \\ 'Department of Otolaryngology, The \\ Second Affiliated Hospital of Nanchang \\ University, NanChang, 330006, JiangXi, \\ People's Republic of China; ${ }^{2}$ Department \\ of Otolaryngology, Nanchang Affiliated \\ Hospital of Sun Yat-Sen University, \\ NanChang, 330009, JiangXi, People's \\ Republic of China
}

Correspondence: Yuehui Liu Email liuyuehuiclark@2Icn.com
Background: A population-based analysis of the risk of secondary primary malignancy (SPM) in patients with hypopharyngeal carcinoma (HPC) has been lacking in the literature. Therefore, we conducted this study to determine the risk factors and assess the effects of SPM on the overall survival (OS) and cancer-specific survival (CSS) of patients with HPC. Methods: Data on selected patients diagnosed with HPC from the Surveillance, Epidemiology and End Results (SEER) database between 1973 and 2015 were examined through logistic regression, Cox regression and nomogram methods.

Results: The overall risk of SPM in patients with HPC was higher than that in the general population (SIR: 2.77; $\mathrm{P}<0.05$ ). The specific-site, including the oral cavity, pharynx, digestive system, respiratory system and endocrine system, had a relatively higher risk of SPM. The overall risks of the subgroup of people 55-75 years of age and all subgroups of sex, race and latency were significantly elevated. In addition, patients with HPC were more likely to have been diagnosed in 2010-2015 (vs 2004-2009; P = 0.002), to be unmarried (vs married; $\mathrm{P}=0.008$ ), to have distant metastasis (vs no metastasis; $\mathrm{P}=0.016$ ) and to have had no surgery for the first tumor (vs surgery for the first tumor; $\mathrm{P}=0.021$ ), and these aspects were associated with a significantly elevated risk of developing SPM. SPM was independently associated with better OS and CSS. The OS and CSS in patients with HPC with SPM were better than those in patients without SPM $(\log \operatorname{rank} \mathrm{P}<0.0001)$. The $\mathrm{C}$ indexes of the nomogram constructed with ten influencing factors including SPM were 0.681:0.699 for OS and 0.705:0.724 for CSS (training cohort:validation cohort).

Conclusion: Although the overall risk of SPM in patients with HPC was elevated, SPM did not decrease the OS and CSS in patients with HPC. This finding is inconsistent with clinical observations and thus requires further research and exploration. It possibly because HPC might have a shorter survival time, or the follow-up time was not long enough.

Keywords: hypopharyngeal carcinoma, HPC, secondary primary malignancy, SPM, SEER, nomogram

\section{Introduction}

Hypopharyngeal carcinoma (HPC) is the most aggressive subtype of head and neck cancer. Over recent decades, the incidence of HPC has increased each year. ${ }^{1}$ In addition, the prognosis of HPC is often poor, because its hidden anatomical location hinders detection. ${ }^{2}$ Currently, HPC treatment remains based on surgical resection, supplemented by adjuvant chemotherapy and radiotherapy. ${ }^{3,4}$ With the continual improvements in diagnostic technology and therapy methods, the survival rates of patients with HPC have also increased. However, with this increased survival time, multiple complications have begun to be observed. ${ }^{5}$ 
Table I Site-Specific Risk of SPM in Patients with HPC

\begin{tabular}{|c|c|c|c|c|}
\hline Site of Second Primary Malignancy & Observed & Expected & SIR & $95 \% \mathrm{Cl}$ \\
\hline All Sites & 1275 & 460.45 & $2.77 \#$ & $2.62-2.93$ \\
\hline All Solid Tumors & 1220 & 412.28 & $2.96 \#$ & $2.80-3.13$ \\
\hline Oral cavity and pharynx & 233 & 12.69 & $18.37 \#$ & $16.08-20.88$ \\
\hline Tongue & 82 & 2.93 & 27.99\# & $22.26-34.74$ \\
\hline Floor of Mouth & 23 & 1.09 & $21.07 \#$ & $|3.36-3| .62$ \\
\hline Nasopharynx & 7 & 0.50 & $14.10 \#$ & $5.67-29.05$ \\
\hline Esophagus & 146 & 6.21 & $23.53 \#$ & $19.87-27.67$ \\
\hline Digestive System & 304 & 95.01 & $3.20 \#$ & $2.85-3.58$ \\
\hline Respiratory System & 479 & 82.89 & $5.78 \#$ & $5.27-6.32$ \\
\hline Bones and Joints & 0 & 0.38 & 0 & $0-9.75$ \\
\hline Soft Tissue including Heart & 5 & 1.97 & 2.54 & $0.83-5.93$ \\
\hline Skin excluding Basal and Squamous & 9 & 14.85 & 0.61 & $0.28-1.15$ \\
\hline Breast & 18 & 23.59 & 0.76 & $0.45-1.21$ \\
\hline Female Genital System & 6 & 9.72 & 0.62 & $0.23-1.34$ \\
\hline Male Genital System & 105 & $|20.3|$ & 0.87 & $0.7 I-1.06$ \\
\hline Urinary System & 51 & 42.20 & 1.21 & $0.90-1.59$ \\
\hline Eye and Orbit & 2 & 0.65 & 3.08 & $0.37-11.11$ \\
\hline Brain and Other Nervous System & 3 & 4.49 & 0.67 & $0.14-1.95$ \\
\hline Endocrine System & 8 & 3.08 & $2.60 \#$ & $1.12-5.12$ \\
\hline Adrenal Gland & 3 & 0.13 & 22.64\# & $4.67-66.18$ \\
\hline Thyroid & 5 & 2.71 & 1.84 & $0.60-4.29$ \\
\hline All Lymphatic and Hematopoietic Diseases & 29 & 36.23 & 0.80 & $0.54-1.15$ \\
\hline Mesothelioma & 0 & 1.45 & 0 & $0-2.54$ \\
\hline Kaposi Sarcoma & 0 & 0.44 & 0 & $0-8.30$ \\
\hline Miscellaneous & 23 & 10.51 & $2.19 \#$ & $1.39-3.29$ \\
\hline
\end{tabular}

Note: ${ }^{\# P<0.05 . ~}$

Table 2 Age at Diagnosis, Sex, Race and Latency Impact on the Overall Risk of Developing SPM in Patients with HPC

\begin{tabular}{|c|c|c|c|c|}
\hline Parameters & Observed & Expected & SIR & $95 \% \mathrm{Cl}$ \\
\hline \multicolumn{5}{|c|}{ Age at diagnosis, years } \\
\hline$\leq 55$ & 275 & 59.98 & 4.58 & $0.89-10.93$ \\
\hline $55-75$ & 896 & 338.23 & $2.65 \#$ & $1.68-3.63$ \\
\hline$\geq 75$ & 104 & 62.26 & 1.67 & $0.58-2.45$ \\
\hline \multicolumn{5}{|l|}{ Sex } \\
\hline Male & 1020 & 379.93 & $2.68 \#$ & $2.52-2.85$ \\
\hline Female & 255 & 80.52 & $3.17 \#$ & $2.79-3.58$ \\
\hline \multicolumn{5}{|l|}{ Race } \\
\hline White & 1006 & 380.52 & $2.64 \#$ & $2.48-2.81$ \\
\hline Black & 197 & 59.71 & $3.30 \#$ & $2.85-3.79$ \\
\hline Other & 72 & 19.79 & $3.64 \#$ & $2.85-4.58$ \\
\hline \multicolumn{5}{|l|}{ Latency } \\
\hline 2-1I months & 165 & 74.22 & $2.22 \#$ & $1.90-2.59$ \\
\hline 12-59 months & 552 & 173.95 & $3.17 \#$ & $2.91-3.45$ \\
\hline $60-119$ months & 333 & 112.34 & $2.96 \#$ & $2.65-3.30$ \\
\hline$\geq 120$ months & 225 & 99.95 & $2.25 \#$ & $1.97-2.57$ \\
\hline
\end{tabular}

Note: ${ }^{*} \mathrm{P}<0.05$. 
Secondary primary malignancy (SPM), a long-term complication of cancer, has received increasing interest in recent years. ${ }^{6,7}$ Numerous studies have shown that SPM often occurs after the treatment of various solid tumors. ${ }^{8,9}$ Previous studies on SPM have focused mostly on other types of head and neck cancer, but rarely on HPC. ${ }^{10,11}$ Smoking, drinking, HPV infection and genetic microenvironmental factors are important influences on the occurrence and development of HPC. ${ }^{12}$ However, the risk factors for SPM in patients with HPC are unclear, and the effects of SPM have not been effectively assessed. With the increase in the number of cancer survivors, the risk of SPM in patients must be assessed to provide insights for the further treatment of cancer. ${ }^{13}$ Our study clarified the overall and site-specific risks of SPM in patients with HPC, assessed the effects of SPM on overall survival (OS) and cancer-specific survival (CSS), and further constructed and verified a nomogram for predicting the 3-year, 5-year and 10-year OS and CSS. Our study provides new evidence of the effects of clinical treatment of SPM in HPC survival.

The Surveillance, Epidemiology, and End Results (SEER) database, affiliated with the National Cancer Institute, collects and reports cancer survival data from several central cancer registries, which manage approximately $30 \%$ of the population in the USA. From the SEER database, we obtained data from a large cohort and conducted a comparative analysis of patients with HPC with vs without SPM, to clarify the effects of SPM on patients with HPC.

\section{Methods}

\section{Patient Selection}

We used the data set Incidence-SEER 9 Regs Research Data, Nov 2017 Sub (1973-2015) <Katrina/Rita Population Adjustment $>$ to analyze the multiple primary

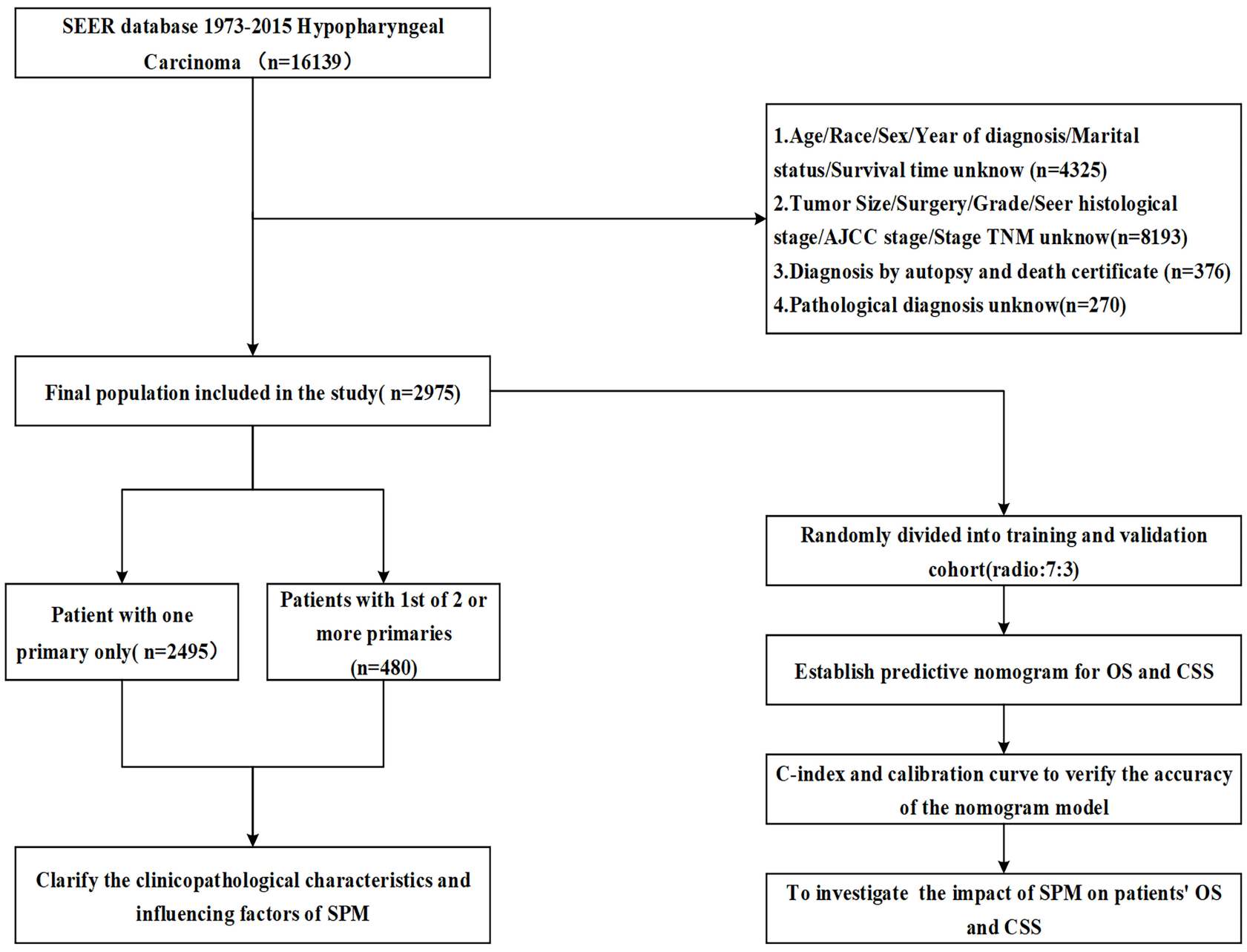

Figure I Flowchart of data selection. 
Table 3 Clinicopathological Characteristics of Patients with HPC as the Lone Primary and Those with HPC as the First of Two or More Primaries

\begin{tabular}{|c|c|c|c|}
\hline & One Primary $(n=2495)$ & First of Two or More Primaries $(n=480)$ & P-value \\
\hline Year of diagnosis & & & 0.027 \\
\hline 2004-2009 & $1248(50.02 \%)$ & 283 (58.96\%) & \\
\hline $2010-2015$ & 1247 (49.98\%) & 197 (4I.04\%) & \\
\hline Age at diagnosis, years & & & 0.140 \\
\hline$<55$ & $54 \mathrm{I}(2 \mathrm{I} .68 \%)$ & 95 (19.79\%) & \\
\hline $55-75$ & 1550 (62.12\%) & 319 (66.46\%) & \\
\hline$\geq 75$ & 404 (16.19\%) & $66(13.75 \%)$ & \\
\hline Sex & & & 0.356 \\
\hline Male & $2035(81.56 \%)$ & $397(82.71 \%)$ & \\
\hline Female & $460(18.44 \%)$ & $83(17.29 \%)$ & \\
\hline Race & & & 0.257 \\
\hline White & $1879(75.31 \%)$ & $364(75.83 \%)$ & \\
\hline Black & 458 (I8.36\%) & $86(17.92 \%)$ & \\
\hline Other & $158(6.33 \%)$ & $30(6.25 \%)$ & \\
\hline Marital status & & & 0.075 \\
\hline Married & II 47 (45.97\%) & $259(53.96 \%)$ & \\
\hline Unmarried & $1348(54.03 \%)$ & $22 \mathrm{I}(46.04 \%)$ & \\
\hline Grade & & & 0.140 \\
\hline Grade I, well differentiated & $120(4.81 \%)$ & $23(4.79 \%)$ & \\
\hline Grade II, moderately differentiated & $\mid 26 \mathrm{I}(50.54 \%)$ & $259(53.96 \%)$ & \\
\hline Grade III, poorly differentiated & $1067(42.77 \%)$ & $193(40.21 \%)$ & \\
\hline Grade IV, undifferentiated & $47(1.88 \%)$ & $5(1.04 \%)$ & \\
\hline SEER histological stage & & & 0.137 \\
\hline Localized & $200(8.02 \%)$ & $5 \mathrm{I}(10.63 \%)$ & \\
\hline Regional & 1393(55.83\%) & $293(61.04 \%)$ & \\
\hline Distant & $902(36.15 \%)$ & |36(28.33\%) & \\
\hline AJCC sixth stage & & & 0.212 \\
\hline I & $76(3.05 \%)$ & $19(3.96 \%)$ & \\
\hline II & $247(9.90 \%)$ & $76(15.83 \%)$ & \\
\hline III & $436(17.47 \%)$ & $93(19.38 \%)$ & \\
\hline IV & $1736(69.58 \%)$ & $292(60.83 \%)$ & \\
\hline Stage $T$ & & & 0.035 \\
\hline TI & $230(9.22 \%)$ & $46(9.58 \%)$ & \\
\hline $\mathrm{T} 2$ & $862(34.55 \%)$ & $211(43.96 \%)$ & \\
\hline T3 & $470(18.84 \%)$ & $86(17.92 \%)$ & \\
\hline T4 & $933(37.39 \%)$ & |37(28.54\%) & \\
\hline Stage N & & & 0.062 \\
\hline No & $659(26.41 \%)$ & $159(33.13 \%)$ & \\
\hline $\mathrm{NI}$ & $538(21.56 \%)$ & $98(20.42 \%)$ & \\
\hline N2 & I I 62(46.57\%) & $204(42.5 \%)$ & \\
\hline N3 & $136(5.45 \%)$ & $19(3.96 \%)$ & \\
\hline Stage M & & & 0.436 \\
\hline Mo & $2292(91.86 \%)$ & $462(96.25 \%)$ & \\
\hline MI & $203(8.14 \%)$ & $18(3.75 \%)$ & \\
\hline
\end{tabular}

(Continued) 
Table 3 (Continued).

\begin{tabular}{|c|c|c|c|}
\hline & One Primary $(n=2495)$ & First of Two or More Primaries $(n=480)$ & P-value \\
\hline Tumor size & & & 0.251 \\
\hline$<2 \mathrm{~cm}$ & $1824(73.11 \%)$ & $358(74.58 \%)$ & \\
\hline $2-5 \mathrm{~cm}$ & $44(1.76 \%)$ & $6(1.25 \%)$ & \\
\hline$>5 \mathrm{~cm}$ & $627(25.13 \%)$ & $116(24.17 \%)$ & \\
\hline Surgery for first primary site & & & 0.348 \\
\hline Yes & $526(21.08 \%)$ & $131(27.29 \%)$ & \\
\hline No & $1969(78.92 \%)$ & $349(72.71 \%)$ & \\
\hline Number of primaries & & & - \\
\hline 2 Primaries & - & $432(90 \%)$ & \\
\hline 3 Primaries & - & $40(8.33 \%)$ & \\
\hline 4 Primaries & - & $7(1.46 \%)$ & \\
\hline 5 Primaries & - & $0(-)$ & \\
\hline 6 Primaries & - & $\mathrm{I}(0.2 \mathrm{I} \%)$ & \\
\hline
\end{tabular}

standardized incidence ratio. The data set Incidence SEER 18 Regs Research Data + Hurricane Katrina Impacted Louisiana Cases, Nov 2017 Sub (1973-2015 varying) was used for case selection. Patients were selected according to the following inclusion criteria: (1) diagnosis confirmed by positive histology; (2) diagnosis of HPC by histopathology; (3) SPM of HPC, indicating that HPC was the first cancer of two or more primary malignancies; (4) availability of complete information for all selected patient variables.

\section{Definition}

With reference to the definition of multiple primary malignancy in the SEER database, the criteria used in our study were as follows: (1) ICD-O-3 histology codes indicating that the first three different tumors were multiple primary malignancies; (2) an invasive tumor diagnosed more than 60 days after the in situ tumor diagnosis, indicating multiple primary malignancies. Latency was defined as the time interval from the diagnosis of HPC to the diagnosis of SPM. The standardized incidence ratio (SIR), an indicator of SPM risk, was calculated by dividing the number of observed SPM cases by the expected number in the general population.

\section{Statistical Analyses}

We used SEER*Stat version 8.3.6 (http://seer.cancer.gov/ seerstat/) to retrieve data from the SEER database. A twoway analysis of variance (ANOVA) was used to compare the means for continuous variables, whereas a chi-squared test was used for categorical variables. Multivariable logistic regression was used to clarify the effects of individual factors on the presence of SPM. Survival estimates were obtained with the Kaplan-Meier method. Multivariable Cox regression was used to analyze the independent factors influencing OS and CSS in patients with HPC. A $\mathrm{P}$-value $<0.05$ was considered statistically significant. SPSS (release 22.0, IBM Corporation, Armonk, NY, USA) was used for statistical analysis, and $\mathrm{R}$ version 4.0.4 (R Foundation) was used for nomograms.

\section{Results}

\section{Risk of SPM at Different Anatomical Sites, According to Age, Sex, Race and Latency} According to our statistical results (Table 1), the overall risk of SPM in patients with HPC was significantly higher than that in the general population (SIR: 2.77; 95\% CI: $2.62-2.93 ; \mathrm{P}<0.05)$. The risk of SPM was significantly elevated in certain areas, including all solid tumors, the oral cavity, pharynx, digestive system, respiratory system, endocrine system and other areas, particularly the tongue, floor of the mouth, nasopharynx, esophagus and adrenal glands. The risk of SPM at other anatomical sites in patients with HPC did not change significantly.

Diagnosis age, sex, race and latency may be factors affecting the SIR of SPM. Therefore, we further evaluated the effects of these factors on the risk of SPM in patients with HPC. As shown in Table 2, in patients 55-75 years of 
Table 4 Multivariable Logistic Regression for the Presence of SPM After HPC Diagnosis

\begin{tabular}{|c|c|c|c|c|}
\hline & \multicolumn{2}{|l|}{ Univariate Analysis } & \multicolumn{2}{|c|}{ Multivariate Analysis } \\
\hline & HR (95\% Cl) & P-value & HR (95\% Cl) & P-value \\
\hline \multicolumn{5}{|l|}{ Year of diagnosis } \\
\hline 2004-2009 & I [Reference] & & I [Reference] & \\
\hline 2010-2015 & I.435(I.I77-I.750) & $<0.001$ & $1.389(1.128-1.711)$ & 0.002 \\
\hline \multicolumn{5}{|l|}{ Age at diagnosis, years } \\
\hline$<55$ & I [Reference] & & & \\
\hline $55-75$ & $0.835(0.665-1.095)$ & 0.212 & - & - \\
\hline$\geq 75$ & I.075(0.765-I.509) & 0.677 & - & - \\
\hline \multicolumn{5}{|l|}{ Sex } \\
\hline Female & I [Reference] & & & \\
\hline Male & $0.925(0.715-1.196)$ & 0.552 & - & - \\
\hline \multicolumn{5}{|l|}{ Race } \\
\hline White & I [Reference] & & & \\
\hline Black & $1.032(0.798-1.333)$ & 0.811 & - & - \\
\hline Other & $1.020(0.680-1.531)$ & 0.923 & - & - \\
\hline \multicolumn{5}{|l|}{ Marital status } \\
\hline Married & I [Reference] & & I [Reference] & \\
\hline Unmarried & $1.377(1.132-1.676)$ & $<0.001$ & $1.308(1.072-1.595)$ & 0.008 \\
\hline \multicolumn{5}{|l|}{ Grade } \\
\hline Grade I, well differentiated & I [Reference] & & & \\
\hline Grade II, moderately differentiated & $0.933(0.586-1.487)$ & 0.771 & - & - \\
\hline Grade III, poorly differentiated & $1.060(0.66 I-1.698)$ & 0.810 & - & - \\
\hline Grade IV, undifferentiated & $1.802(0.647-5.018)$ & 0.260 & - & - \\
\hline \multicolumn{5}{|l|}{ SEER histological stage } \\
\hline Localized & I [Reference] & & & \\
\hline Regional & $1.212(0.870-1.690)$ & 0.256 & - & - \\
\hline Distant & $1.691(1.184-2.415)$ & 0.004 & - & - \\
\hline \multicolumn{5}{|l|}{ AJCC sixth stage } \\
\hline I & I [Reference] & & & \\
\hline II & $0.813(0.462-1.429)$ & 0.471 & - & - \\
\hline III & I.I72(0.676-2.032) & 0.572 & - & - \\
\hline IV & $1.486(0.886-2.494)$ & 0.134 & - & - \\
\hline \multicolumn{5}{|l|}{ Stage $T$} \\
\hline TI & I [Reference] & & & \\
\hline $\mathrm{T} 2$ & $0.817(0.575-1.160)$ & 0.259 & - & - \\
\hline T3 & $1.093(0.739-1.616)$ & 0.656 & - & - \\
\hline T4 & $1.362(0.947-1.960)$ & 0.096 & - & - \\
\hline \multicolumn{5}{|l|}{ Stage $N$} \\
\hline No & I [Reference] & & & \\
\hline $\mathrm{NI}$ & $1.325(1.005-1.746)$ & 0.046 & - & - \\
\hline N2 & I.374(I.094-I.727) & 0.006 & - & - \\
\hline N3 & I.727(I.037-2.877) & 0.036 & - & - \\
\hline \multicolumn{5}{|l|}{ Stage $M$} \\
\hline Mo & I [Reference] & & I [Reference] & \\
\hline MI & $2.273(1.390-3.719)$ & $<0.001$ & $1.911(1.130-3.234)$ & 0.016 \\
\hline
\end{tabular}

(Continued) 
Table 4 (Continued).

\begin{tabular}{|c|c|c|c|c|}
\hline & \multicolumn{2}{|c|}{ Univariate Analysis } & \multicolumn{2}{|c|}{ Multivariate Analysis } \\
\hline & HR (95\% Cl) & P-value & HR (95\% Cl) & P-value \\
\hline \multicolumn{5}{|c|}{ Tumor size } \\
\hline$<2 \mathrm{~cm}$ & I [Reference] & & & \\
\hline $2-5 \mathrm{~cm}$ & $1.439(0.609-3.403)$ & 0.407 & - & - \\
\hline$>5 \mathrm{~cm}$ & $1.061(0.844-1.333)$ & 0.612 & - & - \\
\hline \multicolumn{5}{|c|}{ Surgery for first primary site } \\
\hline Yes & I [Reference] & & I [Reference] & \\
\hline No & $1.405(1.125-1.756)$ & 0.003 & $1.305(1.04 \mathrm{I}-1.637)$ & 0.021 \\
\hline
\end{tabular}

age, the overall risk of SPM increased by 2.65 -fold. After stratification by sex, the risks among men and women increased by 2.68 fold and 3.17 fold, respectively. Among race groups, the risks of white, black and other races increased by 2.64 fold, 3.30 fold and 3.64 fold, respectively. Analysis according to the latency group indicated that the risks of 2-11 months, 12-59 months, 60-119 months and $\geq 120$ months increased by 2.22 fold, 3.17 fold, 2.96 fold and 2.25 fold, respectively.

\section{Characteristics of Patients with and without SPM}

The process of selecting patients is shown in Figure 1. From the SEER database, we selected 2975 patients with HPC, of whom 2495 had only one primary tumor, and the other 480 had HPC as the first tumor among two or more primary malignancies. Table 3 summarizes the

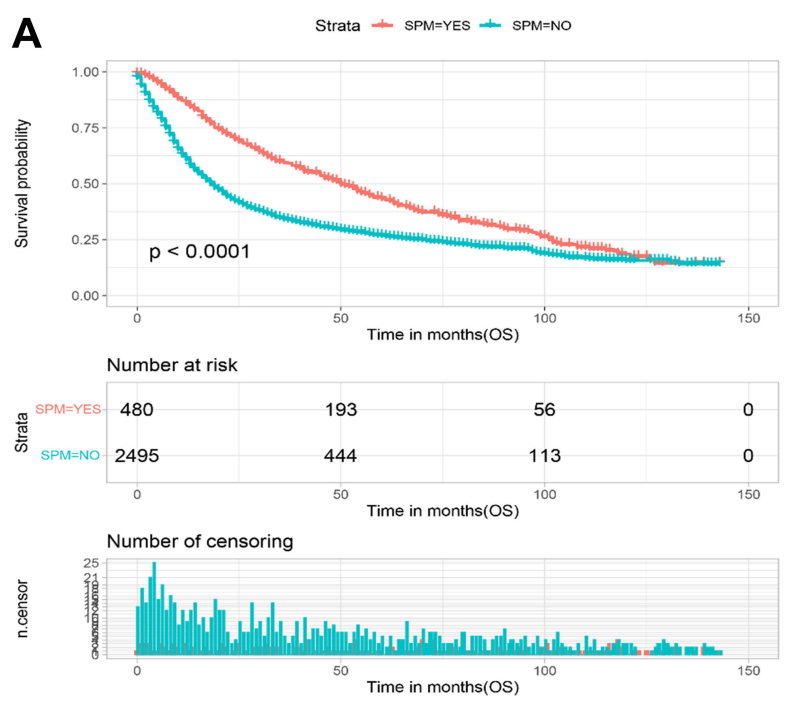

clinicopathological characteristics of patients with HPC as the only primary malignancy and those with HPC as the first tumor among two or more primary malignancies. Among patients with HPC with SPM, 90\% had two primary tumors, and $10 \%$ had at least three primary tumors. According to statistical results, patients with SPM vs without SPM showed a significant difference in year of diagnosis and stage T. However, no significant differences were observed between groups in terms of age, race, sex, marital status, tumor grade, SEER histological stage, American Joint Committee on Cancer (AJCC) sixth stage, stage N, stage M, tumor size and the primary site of surgery.

\section{Risk Factors for SPM}

We used multivariate logistic regression to clarify the risk factors for SPM in patients with HPC. As shown in

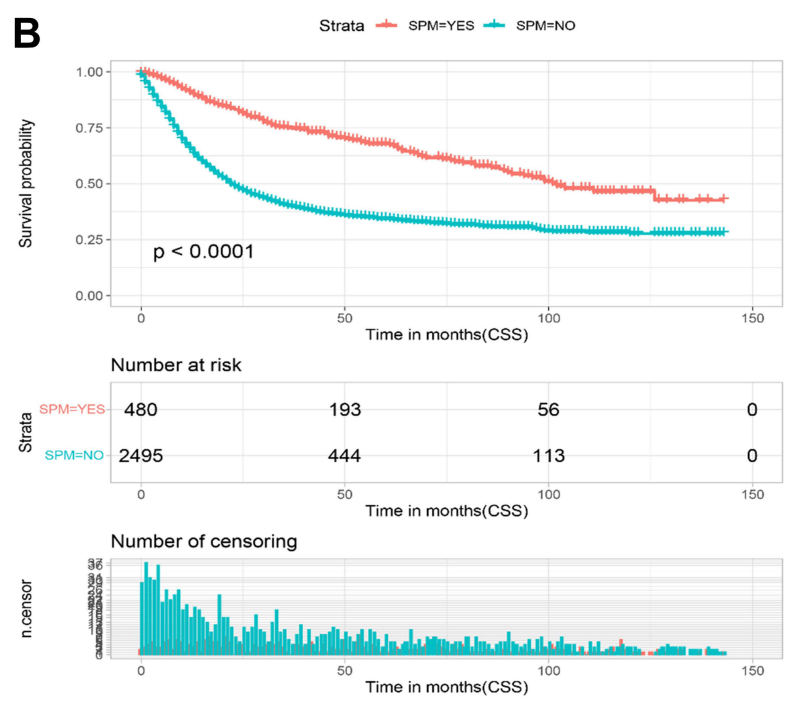

Figure 2 OS and CSS in patients with HPC with or without SPM. (A) OS in patients with HPC with or without SPM (B) CSS in patients with HPC with or without SPM. 
Table 5 Multivariable Cox Regression for OS and CSS in Patients with HPC

\begin{tabular}{|c|c|c|c|c|}
\hline & \multicolumn{2}{|c|}{ Multivariate Analysis (OS) } & \multicolumn{2}{|c|}{ Multivariate Analysis (CSS) } \\
\hline & HR (95\% Cl) & P-value & HR (95\% Cl) & P-value \\
\hline \multicolumn{5}{|l|}{ Year of diagnosis } \\
\hline 2004-2009 & I [Reference] & & I [Reference] & \\
\hline 2010-2015 & $0.882(0.799-0.973)$ & 0.012 & $0.834(0.747-0.934)$ & 0.001 \\
\hline \multicolumn{5}{|l|}{ Age at diagnosis, years } \\
\hline$<55$ & I [Reference] & & I [Reference] & \\
\hline $55-75$ & $1.237(1.103-1.387)$ & $<0.001$ & $1.194(1.050-1.358)$ & 0.007 \\
\hline$\geq 75$ & $2.161(1.865-2.503)$ & $<0.001$ & $1.993(1.686-2.356)$ & $<0.001$ \\
\hline \multicolumn{5}{|l|}{ Sex } \\
\hline Female & I [Reference] & & I [Reference] & \\
\hline Male & $1.077(0.958-1.21 \mathrm{I})$ & - & $1.068(0.935-1.22 I)$ & - \\
\hline \multicolumn{5}{|l|}{ Race } \\
\hline White & I [Reference] & & I [Reference] & \\
\hline Black & $1.368(I .223-1.530)$ & $<0.001$ & $1.343(1.183-1.525)$ & $<0.001$ \\
\hline Other & $0.887(0.734-1.072)$ & - & $0.94 I(0.762-I .163)$ & - \\
\hline \multicolumn{5}{|l|}{ Marital status } \\
\hline Married & I [Reference] & & I [Reference] & \\
\hline Unmarried & $1.402(1.279-1.538)$ & $<0.001$ & $1.396(\mid .256-1.55 \mathrm{I})$ & $<0.001$ \\
\hline \multicolumn{5}{|l|}{ Grade } \\
\hline Grade I, well differentiated & I [Reference] & & I [Reference] & \\
\hline Grade II, moderately differentiated & $0.976(0.789-1.208)$ & - & $0.96 \mathrm{I}(0.755-1.224)$ & - \\
\hline Grade III, poorly differentiated & $0.882(0.711-1.094)$ & - & $0.886(0.694-I .131)$ & - \\
\hline Grade IV, undifferentiated & $0.856(0.573-1.278)$ & - & $0.940(0.608-1.453)$ & - \\
\hline \multicolumn{5}{|l|}{ SEER histological stage } \\
\hline Localized & I [Reference] & & I [Reference] & \\
\hline Regional & $1.063(0.81 \mathrm{I}-1.394)$ & - & $1.037(0.739-1.455)$ & - \\
\hline Distant & $1.066(0.795-1.428)$ & - & $1.06 \mid(0.740-1.523)$ & - \\
\hline \multicolumn{5}{|l|}{ AJCC sixth stage } \\
\hline I & I [Reference] & & I [Reference] & \\
\hline II & $0.969(0.6|7-| .52 \mid)$ & - & I.437(0.769-2.685) & - \\
\hline III & $1.024(0.628-1.669)$ & - & $1.573(0.810-3.056)$ & - \\
\hline IV & $1.098(0.673-1.792)$ & - & $1.859(0.956-3.614)$ & - \\
\hline \multicolumn{5}{|l|}{ Stage $T$} \\
\hline TI & I [Reference] & & I [Reference] & \\
\hline $\mathrm{T} 2$ & $1.477(1.176-1.855)$ & $<0.001$ & $1.48 \mathrm{I}(1.134-1.935)$ & 0.004 \\
\hline T3 & $1.645(1.296-2.0582)$ & $<0.001$ & $1.739(1.322-2.287)$ & $<0.001$ \\
\hline $\mathrm{T} 4$ & $2.158(1.712-2.719)$ & $<0.001$ & $2.313(1.768-3.026)$ & $<0.001$ \\
\hline \multicolumn{5}{|l|}{ Stage $\mathrm{N}$} \\
\hline No & I [Reference] & & I [Reference] & - \\
\hline $\mathrm{NI}$ & I.I37(0.962-1.343) & - & I.I5I(0.953-I.389) & - \\
\hline N2 & I.I54(0.990-I.344) & - & $1.204(1.016-1.429)$ & 0.032 \\
\hline N3 & $1.544(1.228-1.94 I)$ & $<0.001$ & $1.624(1.263-2.088)$ & $<0.001$ \\
\hline \multicolumn{5}{|l|}{ Stage $M$} \\
\hline Mo & I [Reference] & & I [Reference] & \\
\hline MI & $2.335(1.970-2.769)$ & $<0.001$ & $2.286(1.90 I-2.749)$ & $<0.001$ \\
\hline
\end{tabular}

(Continued) 
Table 5 (Continued).

\begin{tabular}{|c|c|c|c|c|}
\hline & \multicolumn{2}{|c|}{ Multivariate Analysis (OS) } & \multicolumn{2}{|c|}{ Multivariate Analysis (CSS) } \\
\hline & HR (95\% CI) & P-value & HR (95\% CI) & P-value \\
\hline \multicolumn{5}{|l|}{ Tumor size } \\
\hline$<2 \mathrm{~cm}$ & I [Reference] & & I [Reference] & \\
\hline $2-5 \mathrm{~cm}$ & $0.982(0.649-1.485)$ & - & $0.983(0.602-1.604)$ & - \\
\hline$>5 \mathrm{~cm}$ & $1.186(1.070-1.314)$ & $<0.01$ & $1.26 I(1.124-1.415)$ & $<0.001$ \\
\hline \multicolumn{5}{|c|}{ Surgery for first primary site } \\
\hline Yes & I [Reference] & & I [Reference] & \\
\hline No & $1.286(1.146-1.442)$ & $<0.001$ & $1.314(1.150-1.502)$ & $<0.001$ \\
\hline \multicolumn{5}{|l|}{ Number of primaries } \\
\hline Multiple primary & I [Reference] & & I [Reference] & \\
\hline One Primary & $1.575(|.39|-1.783)$ & $<0.001$ & $2.435(2.058-2.88 I)$ & $<0.001$ \\
\hline
\end{tabular}

Table 4, a year of diagnosis of 2010-2015 (vs 2004-2009; HR: 1.389; 95\% CI: 1.128-1.711; $\mathrm{P}=0.002)$, being unmarried (vs married; HR: 1.308; 95\% CI: 1.072-1.595; $\mathrm{P}=0.008$ ), having distant metastasis (vs no metastasis; HR: $1.911 ; 95 \% \mathrm{CI}: 1.130-3.234 ; \mathrm{P}=0.016)$ and not having undergone surgery for the first primary tumor (vs having undergone surgery; HR: 1.305 ; 95\% CI: $1.041-$ $1.637 ; \mathrm{P}=0.021$ ) were associated with a significantly greater risk of SPM. Factors including age, race, sex, tumor grade, SEER histological stage, AJCC sixth stage, stage $\mathrm{T}$, stage $\mathrm{N}$ and tumor size were not significantly associated with the development of SPM.

\section{The Effects of SPM on Prognosis}

After clarifying the incidence of SPM and the site-specific risk of SPM, we next explored the effects of SPM on the prognosis of patients with HPC. The OS of patients with SPM was better than that of patients without SPM (logrank $=63.509, \mathrm{P}<0.0001$ ) (Figure 2A). The median OS and the corresponding 95\% CI of patients with SPM and without SPM were 50 (43.163-56.837) months and 19 (17.638-20.362) months, respectively. The CSS of patients with SPM was better than that of patients without SPM $(\log$ rank $=133.233, \mathrm{P}<0.0001)($ Figure $2 \mathrm{~B})$. The median CSS and the corresponding 95\% CI were 102 (81.769122.231) months and 22 (20.022-23.978) months, respectively.

We further used multivariate Cox regression analysis to identify variables that might affect the OS and CSS of patients with HPC. As shown in Table 5, the absence of SPM was an independent factor associated with poorer OS
(HR: 1.575; 95\% CI: 1.391-1.783; P < 0.001). Variables significantly associated with decreased OS were a year of diagnosis of 2004-2009, age 55-75 years, age $\geq 75$ years, black race, unmarried status, stage T2, T3, T4, stage N3, stage M1, tumor size $>5 \mathrm{~cm}$ and no surgery for the first tumor. In addition, as shown in Table 5, the absence of SPM was an independent factor associated with poorer CSS (HR: 2.435; 95\% CI: 2.058-2.881; P $<0.001$ ). Variables significantly associated with decreased CSS were a year of diagnosis of 2004-2009, age 55-75 years and age $\geq 75$ years, black race, unmarried status, stage $\mathrm{T} 2$, T3, T4, stage N2, N3, stage M1, tumor size $>5 \mathrm{~cm}$ and no surgery for the first tumor.

\section{Nomogram for OS and CSS}

We divided all included patients into a training cohort and validation cohort randomly in a ratio of $7: 3$. According to the statistical results in Table 6 , patients in the training cohort vs patients in the validation cohort showed a significant difference in the year of diagnosis, marital status and stage T. Figure $3 \mathrm{~A}$ shows the prognostic nomogram of all important independent predictors of OS in the training cohort of patients with HPC. The prediction C-index for OS was 0.681 and 0.699 in the training cohort and validation cohort, respectively. As shown in Figure 4, the calibration plots for the survival probabilities of patients in the training cohort and validation cohort at 3,5 and 10 years were in agreement. Figure $3 \mathrm{~B}$ shows the prognostic nomogram of important independent predictors of CSS in the training cohort of patients with HPC. The prediction C-index for CSS was 0.705 and 0.724 in the training 
Table 6 Clinicopathological Characteristics of Patients in Training Cohort and Validation Cohort

\begin{tabular}{|c|c|c|c|}
\hline & Training Cohort $(n=2084)$ & Validation Cohort Primaries $(n=891)$ & P-value \\
\hline Year of diagnosis & & & 0.014 \\
\hline 2004-2009 & $1057(50.72 \%)$ & $474(53.20 \%)$ & \\
\hline $2010-2015$ & $1027(49.28 \%)$ & $417(46.80 \%)$ & \\
\hline Age at diagnosis, years & & & 0.160 \\
\hline$<55$ & $445(21.35 \%)$ & $191(21.43 \%)$ & \\
\hline $55-75$ & $13 \mid 4(63.05 \%)$ & $555(62.29 \%)$ & \\
\hline$\geq 75$ & $325(\mid 5.60 \%)$ & $145(\mid 6.27 \%)$ & \\
\hline Sex & & & 0.334 \\
\hline Male & $1687(80.95 \%)$ & $745(83.61 \%)$ & \\
\hline Female & $397(19.05 \%)$ & $146(16.39 \%)$ & \\
\hline Race & & & 0.269 \\
\hline White & $1579(75.77 \%)$ & $664(74.52 \%)$ & \\
\hline Black & $379(18.19 \%)$ & $165(18.52 \%)$ & \\
\hline Other & $126(6.05 \%)$ & $62(6.96 \%)$ & \\
\hline Marital status & & & 0.041 \\
\hline Married & $982(47.12 \%)$ & $424(47.59 \%)$ & \\
\hline Unmarried & $1102(52.88 \%)$ & $467(52.41 \%)$ & \\
\hline Grade & & & 0.148 \\
\hline Grade I, well differentiated & $95(4.56 \%)$ & $48(5.39 \%)$ & \\
\hline Grade II, moderately differentiated & $1065(51.10 \%)$ & $455(51.07 \%)$ & \\
\hline Grade III, poorly differentiated & $888(42.61 \%)$ & $372(41.75 \%)$ & \\
\hline Grade IV, undifferentiated & $36(1.73 \%)$ & $16(1.80 \%)$ & \\
\hline SEER histological stage & & & 0.148 \\
\hline Localized & $167(8.01 \%)$ & $84(9.43 \%)$ & \\
\hline Regional & II $82(56.72 \%)$ & $504(56.57 \%)$ & \\
\hline Distant & $735(35.27 \%)$ & $303(34.01 \%)$ & \\
\hline AJCC sixth stage & & & 0.188 \\
\hline 1 & $64(3.07 \%)$ & $31(3.48 \%)$ & \\
\hline II & $220(10.56 \%)$ & $103(11.56 \%)$ & \\
\hline III & $381(18.28 \%)$ & $\mid 48(|6.6| \%)$ & \\
\hline IV & $1419(68.09 \%)$ & $609(68.35 \%)$ & \\
\hline Stage $T$ & & & 0.035 \\
\hline TI & 194(9.31\%) & $82(9.20 \%)$ & \\
\hline $\mathrm{T} 2$ & $748(35.89 \%)$ & $325(36.48 \%)$ & \\
\hline T3 & $385(18.47 \%)$ & $17 \mid(19.19 \%)$ & \\
\hline $\mathrm{T} 4$ & $757(36.32 \%)$ & $313(35.13 \%)$ & \\
\hline Stage $\mathrm{N}$ & & & 0.060 \\
\hline No & $567(27.21 \%)$ & $25 I(28.17 \%)$ & \\
\hline $\mathrm{NI}$ & $446(21.40 \%)$ & $190(21.32 \%)$ & \\
\hline N2 & $961(46.11 \%)$ & $405(45.45 \%)$ & \\
\hline N3 & $110(5.28 \%)$ & $45(5.05 \%)$ & \\
\hline Stage $M$ & & & 0.456 \\
\hline MO & $1935(92.85 \%)$ & $819(91.92 \%)$ & \\
\hline MI & $149(7.15 \%)$ & $72(8.08 \%)$ & \\
\hline
\end{tabular}

(Continued) 
Table 6 (Continued).

\begin{tabular}{|l|l|l|l|}
\hline & Training Cohort (n= 2084) & Validation Cohort Primaries (n= 89 I) & P-value \\
\hline $\begin{array}{l}\text { Tumor size } \\
<2 \mathrm{~cm}\end{array}$ & & & 0.237 \\
$2-5 \mathrm{~cm}$ & $1513(72.60 \%)$ & $669(75.08 \%)$ & $9(1.01 \%)$ \\
$>5 \mathrm{~cm}$ & $41(1.97 \%)$ & $213(23.91 \%)$ & \\
\hline $\begin{array}{l}\text { Surgery for first primary site } \\
\text { Yes }\end{array}$ & $530(25.43 \%)$ & & $216(24.24 \%)$ \\
No & $441(21.16 \%)$ & $675(75.76 \%)$ & 0.355 \\
\hline $\begin{array}{l}\text { Number of primaries } \\
\text { First of 2 or more Primaries } \\
\text { One Primary }\end{array}$ & $1643(78.84 \%)$ & & $144(16.16 \%)$ \\
\hline
\end{tabular}

cohort and validation cohort, respectively. As shown in Figure 5, the calibration plots for the survival probabilities of patients in the training cohort and validation cohort at 3, 5 and 10 years were in agreement.

\section{Discussion}

In recent years, the number of cancer survivors has increased with advances in diagnosis and treatment technologies; consequently, various long-term cancer complications have attracted increasing attention. ${ }^{14,15}$ As the survival time of cancer patients is prolonged, SPM, a long-term complication, is appearing increasingly frequently. ${ }^{16-18}$ Exploring the prevalence and risk factors for SPM would aid in preventing the occurrence of SPM and in further improving the quality of life of cancer survivors.

With the rapid development of precision medicine, formulating personalized diagnosis and treatment strategies becomes increasingly necessary. Nomograms can integrate statistics and clinicopathological characteristics to predict the effects of various factors on the survival time for patients with malignant tumors. ${ }^{19-21}$ This study included ten independent influencing factors including SPM to establish an HPC OS and CSS nomogram, and further used the C index and calibration curve to verify its better predictability. In previous studies, Ali et al and Shen et al have constructed nomograms to predict the survival of patients with head and neck squamous cell carcinoma and basaloid squamous cell carcinoma, which had not been widely used for HPC because of the wide range of research. ${ }^{22,23}$ Then, Lin et al, Tang, Gong et al and Tian et al constructed nomograms for predicting survival in patients with hypopharyngeal squamouscell carcinoma. ${ }^{12,24,25}$ However, SPM was not included in their nomograms. Our study is the first study of SPM in patients with HPC. We verified the better performance of the $\mathrm{C}$ index of our nomogram (0.681:0.699 for OS and 0.705:0.724 for CSS, training cohort: validation cohort), thus enabling theoretical insights based on large data sets for the clinical treatment of SPM.

Our study showed that the overall risk of SPM in patients with HPC was higher than that in the general population. Notably, the site-specific risk of SPM in the oral cavity, pharynx, digestive system and respiratory system was significantly elevated. Patients 55-75 years of age had an elevated risk of SPM, and the incidence of SPM in all subgroups of sex, race and latency was higher than that in the general population. Given this result, we recommend that patients 55-75 years of age with HPC undergo regular respiratory and digestive endoscopy examinations. Possible reasons for the high rates of SPM in the oral cavity and pharynx are as follows: First, the anatomical locations of the oral cavity, oropharynx, nasopharynx and hypopharynx are in proximity. Second, smoking, drinking and HPV infection are common risk factors for HPC, oral cancer and oropharyngeal cancer. ${ }^{26-28}$ Finally, HPC and oral cancer may be associated with mutations in similar oncogenes. ${ }^{29,30}$

In our study, the respiratory system and digestive system were found to be relatively prone to malignant tumors after HPC, possibly because of their proximate anatomical locations. Moreover, the risk of adrenal tumors in survivors of HPC was also significantly elevated. Previous studies based on the SEER database have shown that adrenal tumors are likely to occur not only after HPC, but also after other endocrine tissue tumors, gastrointestinal tumors and hepatic carcinomas. ${ }^{31}$ In addition, 

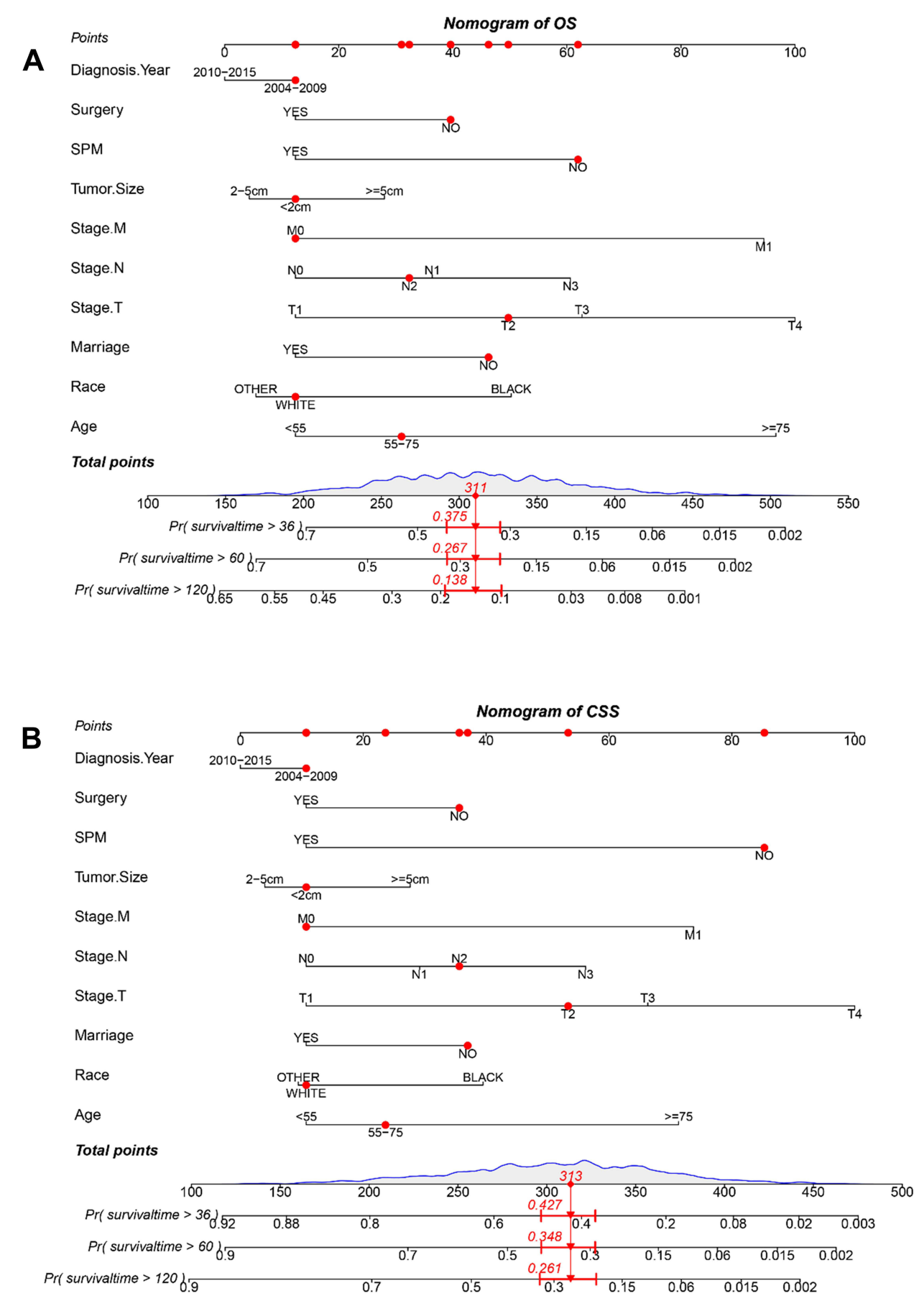

Figure 3 OS nomogram and CSS nomogram in patients with HPC. (A) OS nomogram. (B) CSS nomogram.

previous studies have shown that survivors of Hodgkin's lymphoma, hepatic carcinoma, stomach cancer, kidney cancer and prostate cancer have an increased risk of thyroid cancer. ${ }^{32-36}$ However, our analysis showed that the risk of developing thyroid cancer after HPC did not increase significantly. SEER-based studies have shown that cancer survivors are more likely to develop endocrine system tumors (eg, in the thyroid and adrenal glands). The cause may be associated with changes in hormone levels after the occurrence of the first cancers; however, the specific underlying reasons remain unclear.

Our study also showed that a year of diagnosis of 2010-2015, being unmarried, having stage M1 tumors and not undergoing surgery for the primary tumor were associated with greater risk of SPM. A year of diagnosis of 2010-2015 was more associated with the development of 

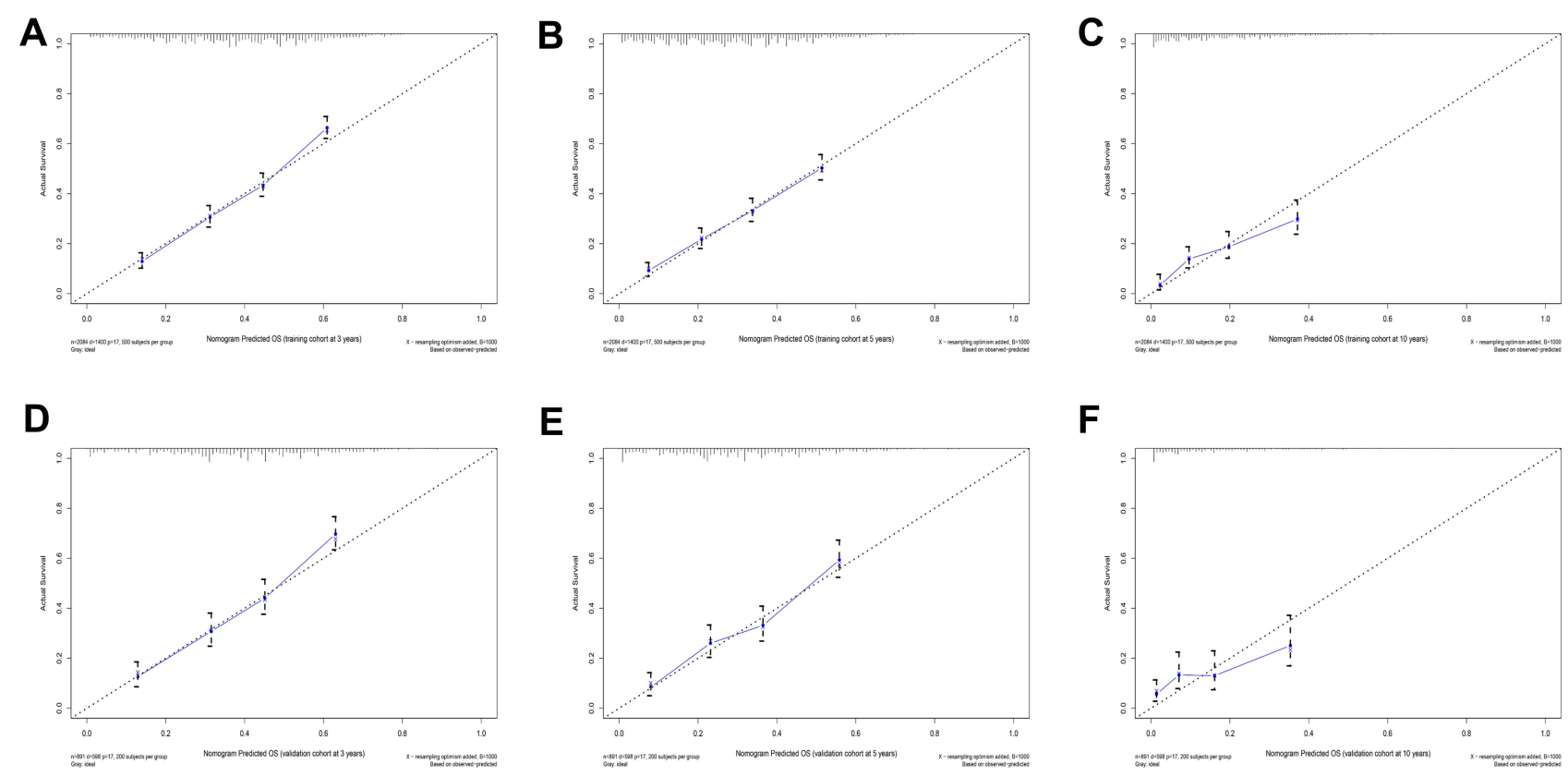

Figure 4 Calibration curve for predicting patient OS at 3, 5, and 10 years. (A-C) Calibration curve for training cohort OS at 3,5,10 years. (D-F) Calibration curve for validation cohort $O S$ at $3,5,10$ years.
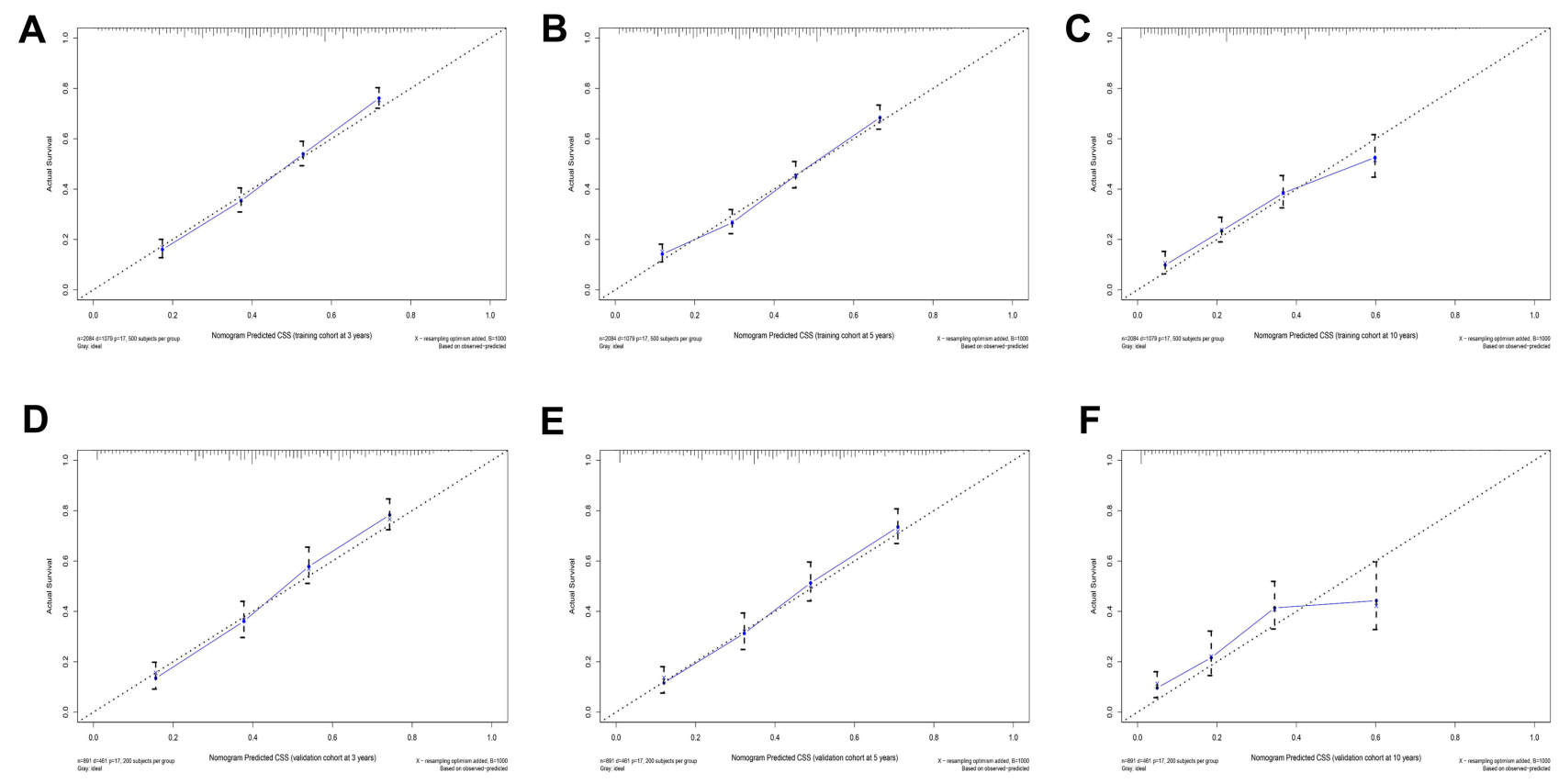

Figure 5 Calibration curve for predicting patient CSS at 3, 5, and 10 years. (A-C) Calibration curve for training cohort CSS at 3, 5, 10 years. (D-F) Calibration curve for validation cohort CSS at $3,5,10$ years.

SPM than a year of diagnosis of 2004-2009. This finding may be because with the development of medical technology enabled better diagnosis and follow-up of SPM in 2010-2015. Having undergone surgery for HPC was an unfavorable factor in the development of SPM. For patients with early stage HPC, surgery is currently the best treatment. ${ }^{37}$ Our results further verify the necessity of surgery for patients with HPC.

Furthermore, we found that SPM was an independent factor associated with the OS and CSS of patients with HPC, and patients with SPM had a better OS and CSS than patients without SPM. In previous studies, patients 
with cholangiocarcinoma with SPM have also been observed to have a better OS and CSS than those without SPM. ${ }^{36}$ Patients with cervical cancer with SPM have been found to experience better OS within 6 years than those without SPM. ${ }^{38}$ However, this result may be inconsistent with clinical observations. The first possible reason for this discrepancy is that HPC might have a shorter survival time than other types of SPM tumors; the second is that the follow-up time might not have been long enough. However, the reason is not yet clear, and further exploration of clinical cases with more detailed information is needed.

Our study is the first to explore the factors influencing SPM in HPC and the effects of SPM on OS and CSS in patients with HPC. However, several study limitations were inevitable. First, because of the lack of information on patients' living habits and family history, the possibility of evaluating more factors influencing SPM was limited. Second, the number of patients with HPC with complete information for each variable in the plus database containing radiotherapy and chemotherapy was relatively small. In order to make the results more reliable, our study did not include radiotherapy and chemotherapy information. Third, although the SPM that we included was in patients who were more than 2 months after the diagnosis of HPC, the recurrence and metastasis of HPC could not be completely ruled out. However, SPM is strictly defined in the SEER database, which is one of the best cancer registration systems in the worldwide.

\section{Conclusion}

We found that patients with HPC have a higher overall risk of SPM than the general population. The specific sites where the risk of SPM was elevated included all solid tumors, particularly the oral cavity, pharynx, digestive system, respiratory system and adrenal glands. The OS and CSS were longer for patients with SPM than without SPM, possibly because HPC might have a shorter survival time, or the follow-up time was not long enough. Therefore, for patients with HPC, especially those aged 55-75 years, digestive system endoscopy, respiratory system endoscopy and adrenal CT should be considered to detect the formation of SPM.

\section{Ethical Statement}

The patient information in the SEER database is obtained anonymously and publicly, and the patient's informed consent is not required. Our work was conducted in accordance with the Declaration of Helsinki (2013), and was approved by the Ethics Committee of the Second Affiliated Hospital of Nanchang University (The Examination and Approval No. Review [2021] No. (009)).

\section{Acknowledge}

The authors acknowledge the efforts of the SEER Program cancer registries in creating the SEER database.

\section{Author Contributions}

All authors contributed to study design, data collection, statistical analysis, drafting or revising the article, have agreed on the journal to which the article will be submitted, gave final approval of the version to be published, and agree to be accountable for all aspects of the work.

\section{Funding}

The National Natural Science Fund of China supported this study (Grant No. 81760184 and 82060185).

\section{Disclosure}

All authors declare that no conflicts of interest in this work.

\section{Reference}

1. Siegel RL, Miller KD, Jemal A. Cancer statistics, 2020. CA Cancer J Clin. 2020;70(1):7-30. doi:10.3322/caac.21590

2. Kwon DI, Miles BA. Hypopharyngeal carcinoma: do you know your guidelines? Head Neck. 2019;41(3):569-576. doi:10.1002/hed.24752

3. Marur S, Forastiere AA. Head and neck squamous cell carcinoma: update on epidemiology, diagnosis, and treatment. Mayo Clin Proc. 2016;91(3):386-396. doi:10.1016/j.mayocp.2015.12.017

4. Tassler AB, Gooding WE, Ferris RL. Hypopharyngeal cancer treatment: does initial surgery confer survival benefit? Head Neck. 2019;41(7):2167-2173. doi:10.1002/hed.25687

5. Cramer JD, Burtness B, Le QT, Ferris RL. The changing therapeutic landscape of head and neck cancer. Nat Rev Clin Oncol. 2019;16 (11):669-683. doi:10.1038/s41571-019-0227-z

6. Huang S, Yang J, Fong S, Zhao Q. Artificial intelligence in cancer diagnosis and prognosis: opportunities and challenges. Cancer Lett. 2020;471:61-71. doi:10.1016/j.canlet.2019.12.007

7. Schoots IG, Padhani AR. Personalizing prostate cancer diagnosis with multivariate risk prediction tools: how should prostate MRI be incorporated? World J Urol. 2020;38(3):531-545. doi:10.1007/ s00345-019-02899-0

8. Wang W. Increased incidence of second primary malignancy in patients with malignant astrocytoma: a population-based study. Biosci Rep. 2019;39(6):Jun. doi:10.1042/BSR20181968

9. Davis EJ, Beebe-Dimmer JL, Yee CL, Cooney KA. Risk of second primary tumors in men diagnosed with prostate cancer: a populationbased cohort study. Cancer. 2014;120(17):2735-2741. doi:10.1002/ cncr.28769

10. Lee DH, Roh JL, Baek S, et al. Second cancer incidence, risk factor, and specific mortality in head and neck squamous cell carcinoma. Otolaryngol Head Neck Surg. 2013;149(4):579-586. doi:10.1177/ 01945998134963.73 
11. Baxi SS, Pinheiro LC, Patil SM, Pfister DG, Oeffinger KC, Elkin EB Causes of death in long-term survivors of head and neck cancer. Cancer. 2014;120(10):1507-1513. doi:10.1002/cncr.28588

12. Smits HJG, Assili S, Kauw F, Philippens MEP, de Bree R, Dankbaar JW. Prognostic imaging variables for recurrent laryngeal and hypopharyngeal carcinoma treated with primary chemoradiotherapy: a systematic review and meta-analysis. Head Neck. 2021;43(7):22022215. doi: $10.1002 /$ hed. 26698

13. Keegan THM, Bleyer A, Rosenberg AS, Li Q, Goldfarb M. Second primary malignant neoplasms and survival in adolescent and young adult cancer survivors. JAMA Oncol. 2017;3(11):1554-1557. doi:10.1001/jamaoncol.2017.0465

14. Siegel R, Naishadham D, Jemal A. Cancer statistics, 2013. CA Cancer J Clin. 2013;63(1):11-30. doi:10.3322/caac.21166

15. Cowens-Alvarado R, Sharpe K, Pratt-Chapman M, et al. Advancing survivorship care through the National Cancer Survivorship Resource Center: developing American Cancer Society guidelines for primary care providers. CA Cancer J Clin. 2013;63(3):147-150. doi:10.3322/ caac. 21183

16. Khanal A, Budhathoki N, Singh VP, Shah BK. Second primary malignancy in bladder carcinoma - A Population-based Study. Anticancer Res. 2017;37(4):2033-2036. doi:10.21873/ anticanres. 11548

17. Liang F, Zhang S, Xue H, Chen Q. Risk of second primary cancers in cancer patients treated with cisplatin: a systematic review and metaanalysis of randomized studies. BMC Cancer. 2017;17(1):871. doi:10.1186/s12885-017-3902-4

18. Fleury I, Chevret S, Pfreundschuh M, et al. Rituximab and risk of second primary malignancies in patients with non-Hodgkin lymphoma: a systematic review and meta-analysis. Ann Oncol. 2016;27 (3):390-397. doi:10.1093/annonc/mdv616

19. Balachandran VP, Gonen M, Smith JJ, DeMatteo RP. Nomograms in oncology: more than meets the eye. Lancet Oncol. 2015;16(4):e173e180. doi:10.1016/s1470-2045(14)71116-7

20. Necchi A, Sonpavde G, Lo Vullo S, et al. Nomogram-based prediction of overall survival in patients with metastatic urothelial carcinoma receiving first-line platinum-based chemotherapy: Retrospective International Study of Invasive/Advanced Cancer of the Urothelium (RISC). Eur Urol. 2017;71(2):281-289. doi:10.1016/ j.eururo.2016.09.042

21. Pan JJ, Ng WT, Zong JF, et al. Prognostic nomogram for refining the prognostication of the proposed 8th edition of the AJCC/UICC staging system for nasopharyngeal cancer in the era of intensity-modulated radiotherapy. Cancer. 2016;122(21):3307-3315. doi:10.1002/ cncr.30198

22. Ali AN, Switchenko JM, Kim S, Kowalski J, El-Deiry MW, Beitler JJ. A model and nomogram to predict tumor site origin for squamous cell cancer confined to cervical lymph nodes. Cancer. 2014;120 (22):3469-3476. doi:10.1002/cncr.28901

23. Shen W, Sakamoto N, Yang L. Cause-specific mortality prediction model for patients with basaloid squamous cell carcinomas of the head and neck: a competing risk analysis. $J$ Cancer. 2018;9 (21):4009-4017. doi:10.7150/jca.20274
24. Tang X, Pang T, Yan WF, Qian WL, Gong YL, Yang ZG. A novel prognostic model predicting the long-term cancer-specific survival for patients with hypopharyngeal squamous cell carcinoma. BMC Cancer. 2020;20(1):1095. doi:10.1186/s12885-020-07599-2

25. Tian S, Li Q, Li R, et al. Development and validation of a prognostic nomogram for hypopharyngeal carcinoma. Front Oncol. 2021;11:696952. doi:10.3389/fonc.2021.696952

26. Ndiaye C, Mena M, Alemany L, et al. HPV DNA, E6/E7 mRNA, and p16INK4a detection in head and neck cancers: a systematic review and meta-analysis. Lancet Oncol. 2014;15(12):1319-1331. doi:10.1016/s1470-2045(14)70471-1

27. Kawakita D, Matsuo K. Alcohol and head and neck cancer. Cancer Metastasis Rev. 2017;36(3):425-434. doi:10.1007/s10555017-9690-0

28. Wookey VB, Appiah AK, Kallam A, Ernani V, Smith LM, Ganti AK. HPV status and survival in non-oropharyngeal squamous cell carcinoma of the head and neck. Anticancer Res. 2019;39(4):1907-1914. doi:10.21873/anticanres.13299

29. Gazdzicka J, Golabek K, Strzelczyk JK, et al. Selected CDKN2A and MDM2 polymorphisms in oral cavity cancer. Acta Biochim Pol. 2020;67(2):213-218. doi:10.18388/abp.2020_5195

30. Misawa K, Mima M, Imai A, et al. The neuropeptide genes SST, TAC1, HCRT, NPY, and GAL are powerful epigenetic biomarkers in head and neck cancer: a site-specific analysis. Clin Epigenetics. 2018;10:52. doi:10.1186/s13148-018-0485-0

31. Rashed WM, Saad AM, Al-Husseini MJ, et al. Incidence of adrenal gland tumor as a second primary malignancy: SEER-based study. Endocr Connect. 2018;7:1040-1048. doi:10.1530/EC-18-0304

32. Abdel-Rahman O. Risk of subsequent primary kidney cancer after another malignancy: a Population-based Study. Clin Genitourin Cancer. 2017;15(5):e747-e754. doi:10.1016/j.clgc.2017.02.004

33. Bezak E, Takam R, Yeoh E, Marcu LG. The risk of second primary cancers due to peripheral photon and neutron doses received during prostate cancer external beam radiation therapy. Phys Med. 2017;42:253-258. doi:10.1016/j.ejmp.2017.02.018

34. Chowdhry AK, Fung C, Chowdhry VK, et al. A population-based study of prognosis and survival in patients with second primary thyroid cancer after Hodgkin lymphoma. Leuk Lymphoma. 2018;59 (5):1180-1187. doi:10.1080/10428194.2017.1369063

35. Morais S, Antunes L, Bento MJ, Lunet N. Risk of second primary cancers among patients with a first primary gastric cancer: a population-based study in North Portugal. Cancer Epidemiol. 2017;50:8591. doi:10.1016/j.canep.2017.08.007

36. Zhuang L, Yan X, Meng Z. Second primary malignancy in patients with cholangiocarcinoma: a population-based study. Cancer Manag Res. 2019;11:1969-1983. doi:10.2147/CMAR.S187614

37. Eckel HE, Bradley PJ. Treatment options for hypopharyngeal cancer. Adv Otorhinolaryngol. 2019;83:47-53. doi:10.1159/000492308

38. Li R, Zhang Y, Ma B, Tan K, Lynn HS, Wu Z. Survival analysis of second primary malignancies after cervical cancer using a competing risk model: implications for prevention and surveillance. Ann Transl Med. 2021;9(3):239. doi:10.21037/atm-20-2003

International Journal of General Medicine

\section{Dovepress}

\section{Publish your work in this journal}

The International Journal of General Medicine is an international, peer-reviewed open-access journal that focuses on general and internal medicine, pathogenesis, epidemiology, diagnosis, monitoring and treatment protocols. The journal is characterized by the rapid reporting of reviews, original research and clinical studies

across all disease areas. The manuscript management system is completely online and includes a very quick and fair peer-review system, which is all easy to use. Visit http://www.dovepress.com/ testimonials.php to read real quotes from published authors. 